\title{
Current Status of Indian Open Access Institutional Repositories (OAIRs) and Its significance in Pandemic Era
}

\author{
Subhajit Panda ${ }^{1}$ and Noble ${ }^{2}$ \\ ${ }^{1}$ Central Library, Chandigarh University, Mohali, Punjab, INDIA \\ ${ }^{2}$ College Library, BLM Girls College, S.B.S. Nagar, Punjab, INDIA \\ e-mail: suvapanda007@gmail.com; noblewatts058@gmail.com
}

\begin{abstract}
The COVID-19 outbreak has affected the world among all segments of the population in all possible fields of life, viz health, economic, social \& educational. In India, the second wave of the pandemic brings the nightmare on repeat with a tsunami of cases. To encounter this critical situation and to safeguard the health of the students \& faculty members, the education system undergoes a significant change, from conventional classroom-based learning to online interaction-based teaching-learning. This turnabout demands the availability of sufficient e-content. In this situation, OAIRs as a free-to-use platform with a voluminous amount of data, are able to help users including the institutions in coping with financial critical situations as well as enabling the learning process. This study aims to determine the current status of Indian OAIR housed in OpenDOAR by conducting a user survey to assess its importance in assisting academics and the education system during this current pandemic situation. The findings of the study reveal that DSpace (58\%) is the dominant software in Indian OAIRs while English (96.43\%) is the most prominent language. Additionally, the study also identifies the continual growth of Indian OAIRs with regular updation. According to the survey result, library staff and researchers are the most experienced regarding the importance and benefits of OAIRs, whereas students need to be more aware. Overall, the survey agrees with the fact that, in India, OAIRs support the significant change in the education system as well as promote web accessibility and eliminate the digital divide.
\end{abstract}

Keywords: COVID-19, Digital divide, Education system, Indian Institutional repositories, Open access, OAIRs, OpenDOAR, Web accessibility

\section{INTRODUCTION}

"Socrates once said 'An unexamined life is not worth living'. Universities fail in this regard. Institutional repositories should be the means by which a university examines itself." - Robert Koob, Provost and Vice-President of Academic Affairs, California Polytechnic State University (Tamminga 2009)

Open access journal \& Institutional repositories are the two primary platform where a researcher can make his research papers publicly accessible. The origin of the open access institutional repositories (OAIRs) is primarily associated with the "crisis in scholarly communication", which is characterized by the rising cost of providing access to scholarly 
publication and the increased restrictions on usage of scholarly material in the electronic environment (Panda 2020). Another major intention to build up an OAIR is to centralize \& preserve the knowledge of the parent institution and facilitates anyone to access the knowledge hub just with internet access (Kathleen 2002). Most of the OAIRs offers a selfarchiving facility and a minimum set of necessary services, e.g., deposit, download, search and access control.

On another side, the spread of the novel coronavirus COVID-19 has wreaked havoc on social contact \& organisation worldwide, and the education sector is no exception (Murphy 2020). In India, with its deadly second wave, the education system faced a catastrophic collapse due to inevitable issues viz. loss of communication; shut down of school, college and universities; disruption of the formal learning process; unavailability of print materials and so on. It provokes the transformation of the learning process from conventional to digital. Such transition requires adequate availability of e-resources to support the education system. In such a financially critical situation, OAIRs provide an alternate way with a huge volume of openly accessible contents that assists students, researchers, faculty members \& library professionals in completing their assignments, acting as a research assistant, supporting the teaching-learning process $\&$ satisfying user information need respectively.

The current research aims to identify the current status of OAIR in India housed in OpenDOAR and conduct a users' survey to evaluate its significance in support the academics \& education system in this pandemic situation. The OpenDOAR is a qualityassured, global Directory of open access repositories that provide free $\&$ open access to academic outputs and resources developed in 2005 with collaboration with the University of Nottingham and Lund University and sponsored by OSI, Jisc, SPARC Europe \& CURL (OpenDOAR n.d.).

\section{OAIR \& ITS FUNCTIONAL ENTITIES}

Open Access $(O A)$ repositories have attracted attention over the past several years, often as a significant way to promote open access to scholarly communication (Bhat 2010). As defined by the Scholarly Publishing \& Academic Resources Coalition position paper, open access institutional repositories (OAIRs) were created to encourage scholarly communication outside traditional publishing models, demonstrate the prestige of institutions by highlighting their scholarly output, and to make this output accessible to the wider academic community (Crow 2002). Another definition is, "an online database ... that makes the full text of items (or complete files) it contains freely and immediately available without any access restrictions" (Pinfield 2005).

This section aims to use the OAIS functional model to provide a more comprehensive overview of the functional entities of an IR. The formation of an IR can be classified into some common functional entities \& six specific functional entities and related interfaces. 


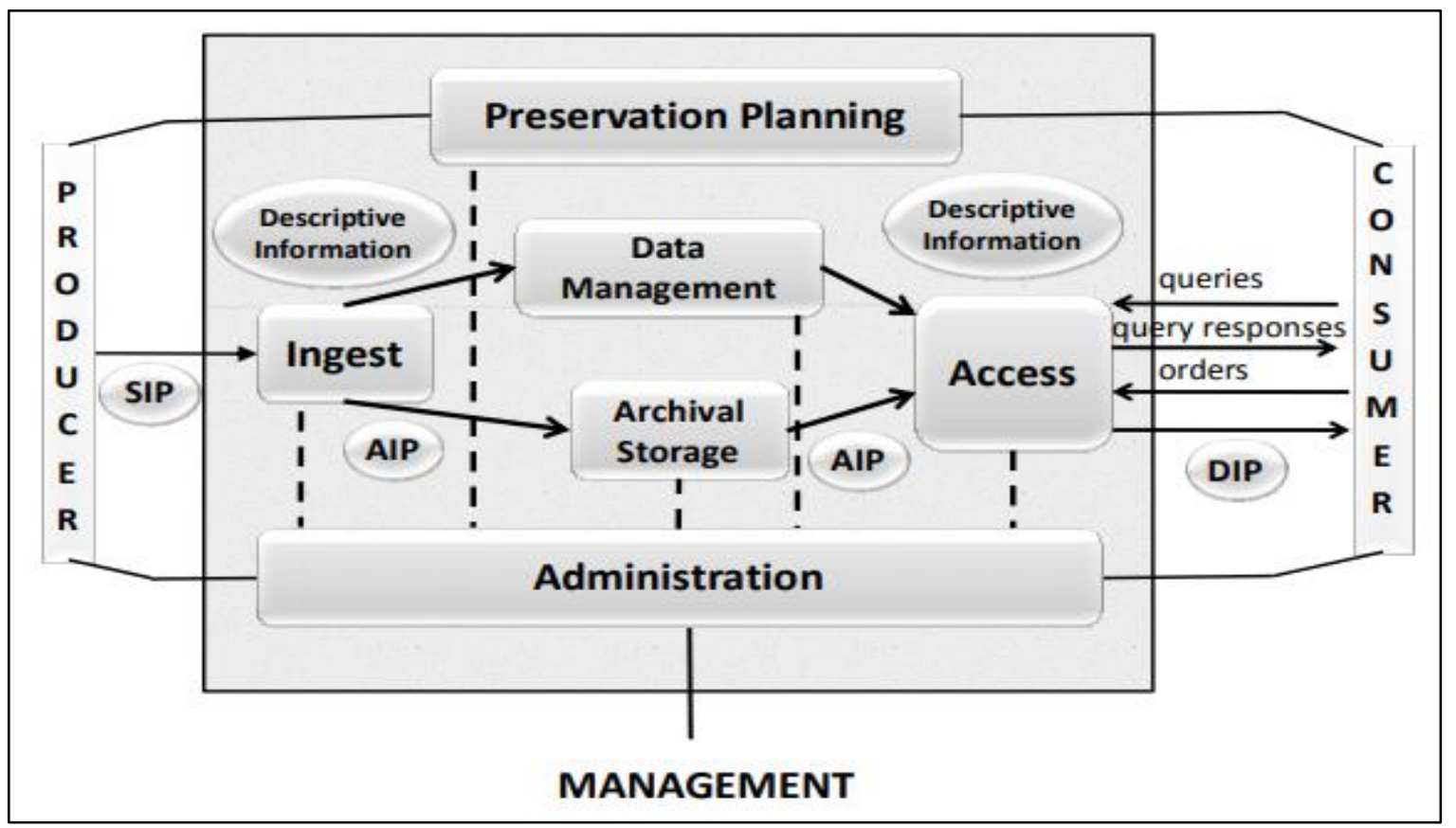

Figure 1: Functional Model of an IR (CCSDS 2012)

The role provided by each of the entities (in figure 1) is described briefly as follows:

(i) Common Services: Modern multifunctional \& diversely distributed computing applications are interconnected with several supporting services. These common services are responsible for the completion of much excellent work. In the case of IR, Operating system services, Network services \& Security services are includes in common services.

(ii) Ingest: Ingest covers the acceptance of submission information, performing quality checking on the data, generating an archival information package that complies with formatting and documentation standards and extracting and managing descriptive information for data updation and management.

(iii) Archival Storage: The Archival Storage Functional Entity provides the services and functions for the storage, maintenance and retrieval of Archival Information Packages (AIPs). After receiving AIPs from Ingest, Archival Storage adds them to permanent storage and provides the capability to reproduce the media over time, perform error checking, ensure disaster recovery and provide data as requested.

(iv) Data Management: Populating, maintaining \& accessioning descriptive information \& administrative data are enables by the Data Management functional entity. Database Management responsibilities include administering the Archive database functions, performing database updates, performing queries, generate query responses, and producing reports from these query responses.

(v) Administration: The Administration Functional Entity provides the services and functions for the overall operation of the Archive system. Administration functions 
include soliciting \& negotiating submission agreements, auditing submissions, maintaining archive standards \& policies, maintaining configuration management of hardware $\&$ software, monitor $\&$ improve archive operations and inventory.

(vi) Preservation Planning: Preservation Planning includes monitoring user groups, emerging technologies, standards and platforms. The objective is to protect against obsolescence, develop preservation strategies and migration plans as required.

(vii) Access: The Access functional entity supports the users by providing detailed information about the existence, description, location and availability of information stored in the IR. Access is all about supporting users of the repository to identify, locate and retrieve the data they require.

\section{LITERATURE REVIEW}

At an early stage, Kalbande (2012) discussed the concept of institutional repository (IR), its need, importance, benefits, critical issues, major problems in the establishment \& maintenance of IR, the role of librarians, intellectual society, academic institutions and the government. Lee et al. (2015) explored the efficiency of an IR to make scholarly publication openly accessible, using 170 journal articles as a study sample, and the Diginole Commons repository of Florida State University as a sample IR. With the help of OpenDOAR, Gul, Bashir, and Ganaie (2019) explored the status of IRs in the South Asian region and also studied the various characteristic features of IRs. The findings of the study suggested that India, Sri Lanka and Bangladesh lead other South Asian nations in terms of IRs count. Kalbande (2019) identified 84 Institutional Repositories of India from OpenDOAR and ROAR directory and presented Indian scenario by analyzing them using criteria like IR type, present status, software used, items available, subject classification \& language. Adewole-Odeshi and Ezechukwu (2020) analyzed the OpenDoar directory to examine the growth of open access institutional repositories in Nigeria over the period 2009-2019. The study sample consists of 25 OAIR with 68,610 uploaded documents between these 10 years. Another study by Nayak et al. (2021) focused on the current status of SCO countries Open Access Institutional Repositories housed in Opendoar. The study findings revealed the identification of 214 repositories with the top registrations in 2011 and 2019, amidst 36 (16.82\%) and 34 (15.89\%), respectively. The paper of Gurikar and Hadagali (2021) determined the use of Open Source Software (OSS) in building Indian Institutional Repositories in different types of institutions, Indian States / UTs and different disciplines. A total of 209 Open Access Repositories were identified from Open DOAR, ROAR, AGRIS and LIS link Kerala. The outcomes of the study revealed that Dspace and Eprints are the most used OSS in Indian Institutional Repositories. The study of Shajitha and Majeed (2021) evaluated the institutional repositories (IRs) in South India in terms of policy and procedures, technology, content and contributors, promotion \& assessment and personnel. Furthermore, the content growth of each of the 23 identified IRs were monitored for a year (from February 2018 to January 2019).

\section{STUDY RATIONALE}


All of the studies above investigated different aspects of open access institutional repositories (OAIR), from their significance $\&$ characteristics to their usefulness in making the Web more accessible. Considering the current Pandemic situation, OAIR plays an important role as a knowledge hub, freely available \& accessible on the Web. However, no such research has been conducted directing particularly on this area. The focus of the current paper is to identify the significance of OAIR in this pandemic era after identifying the current status of Indian OAIR from the OpenDOAR directory.

\section{STUDY OBJECTIVES}

After thoroughly analyze the past researches \& determined the study rationale, the objectives of the present study identifies as follows,

1) To study the current status of Indian OAIRs according to OpenDOAR database

a) To find out the year-wise growth of Indian OAIRs

b) To highlights the state wise distribution of Indian OAIRs

c) To identify the various software used for creations of Indian OAIRs

d) To know the different content types, subject area \& languages of Indian OAIRs

e) To check the updation regularity of Indian OAIRs

2) To examine the effectiveness of Indian OAIRs during pandemic era through users' survey

\section{RESEARCH METHEDOLOGY}

The research design of the current research is based on determining the current status of Indian OAIRs in OpenDOAR and the effectiveness of OAIRs to support the Indian education system in this pandemic situation. OpenDOAR currently covers a total of 98 Indian repositories, 84 of which are institutional repositories (see figure 2). OpenDOAR was analyzed to get statistics of institutional repositories in India based upon parameters like year-wise growth, state-wise distribution, software types, subject areas, languages and last modified. The users' perspective determined by conducting a short survey. The survey questionnaire was designed upon a structured research questionnaire created through Google form (https://forms.gle/5f4E7GBRjiVTUK1g8) and circulated online via email to the targeted sample groups viz, Students, Researchers, Faculty Members \& Library Professionals of all over India. It took almost two months and distributed over 600 targeted sample groups of which $538(89.67 \%)$ took part in this survey from a different region of India. Among which, a total of 500 people was selected as a final study sample (i.e. 125 for each single sample type) and among them, 311(62\%) Female, 158(32\%) Male, $\& 31(6 \%)$ choose to prefer not to say about their gender (see figure 3 ). 
Types of Indian Repository in OpenDOAR

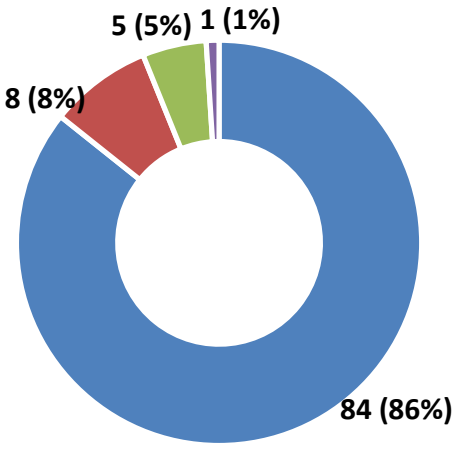

- Institutional $\mid$ Disciplinary $\|$ Aggregating - Governmental

Figure 2: Types of Indian Repositories in OpenDOAR

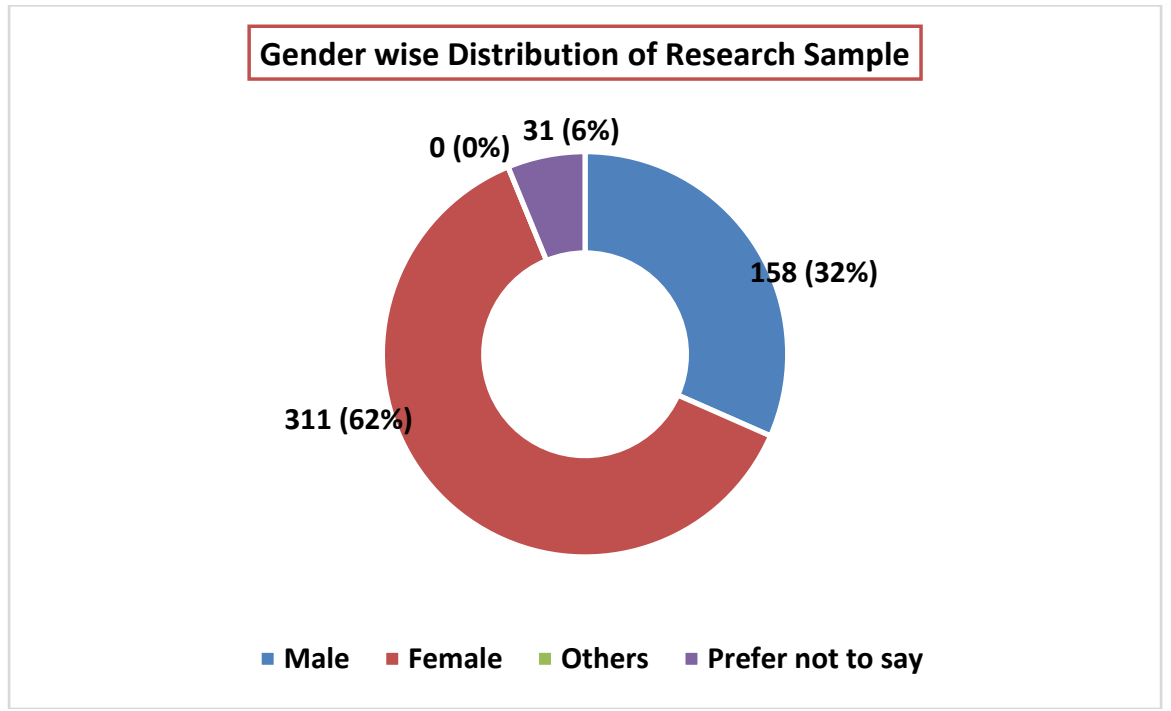

Figure 3: Gender Wise Distribution of Research Sample

\section{INSTITUTIONAL REPOSITORIES IN INDIA: AN ANALYSIS OF THE CURRENT STATUS}

To examine the current status of Indian OAIRs, statistics from OpenDOAR collected, categorized \& explained according to some notable parameters viz. Year-wise growth, State-wise distribution, used software types, covered content types, language types, subject areas and updation regularity.

\section{Growth of OAIRs Year Wise}




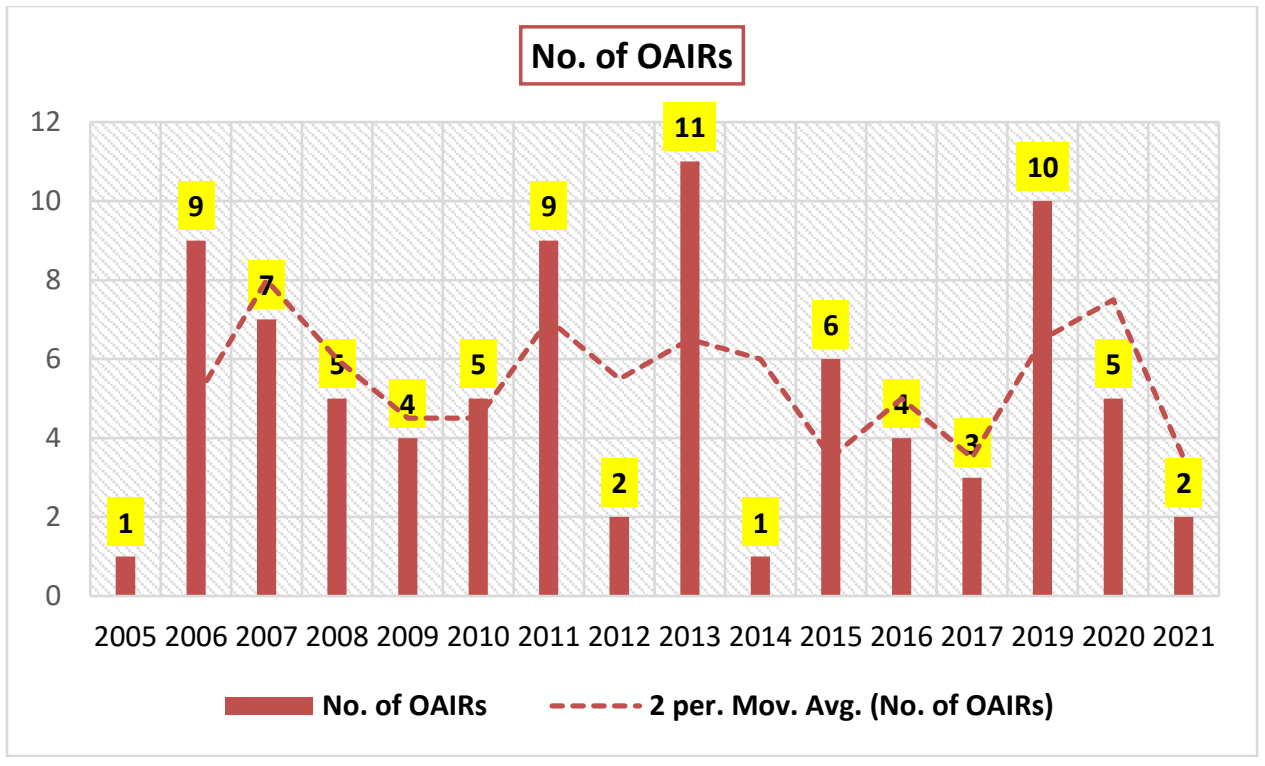

Figure 4: Year-wise Growth of Indian OAIRs

The figure 4 represents the growth of Indian OAIRs in OpenDOAR since its development. According to the statistics, a maximum number of Indian OAIRs developed in the year 2013 (i.e. 11) followed by 2019, 2011 \& 2006 produced 10, 9 \& 9 OAIRs, respectively. As of 2021, in OpenDOAR, till now two repositories are covered this year and a total of 84 . Again, the figure of cumulative growth confirms the consistency of continual addition of OAIRs in OpenDOAR.

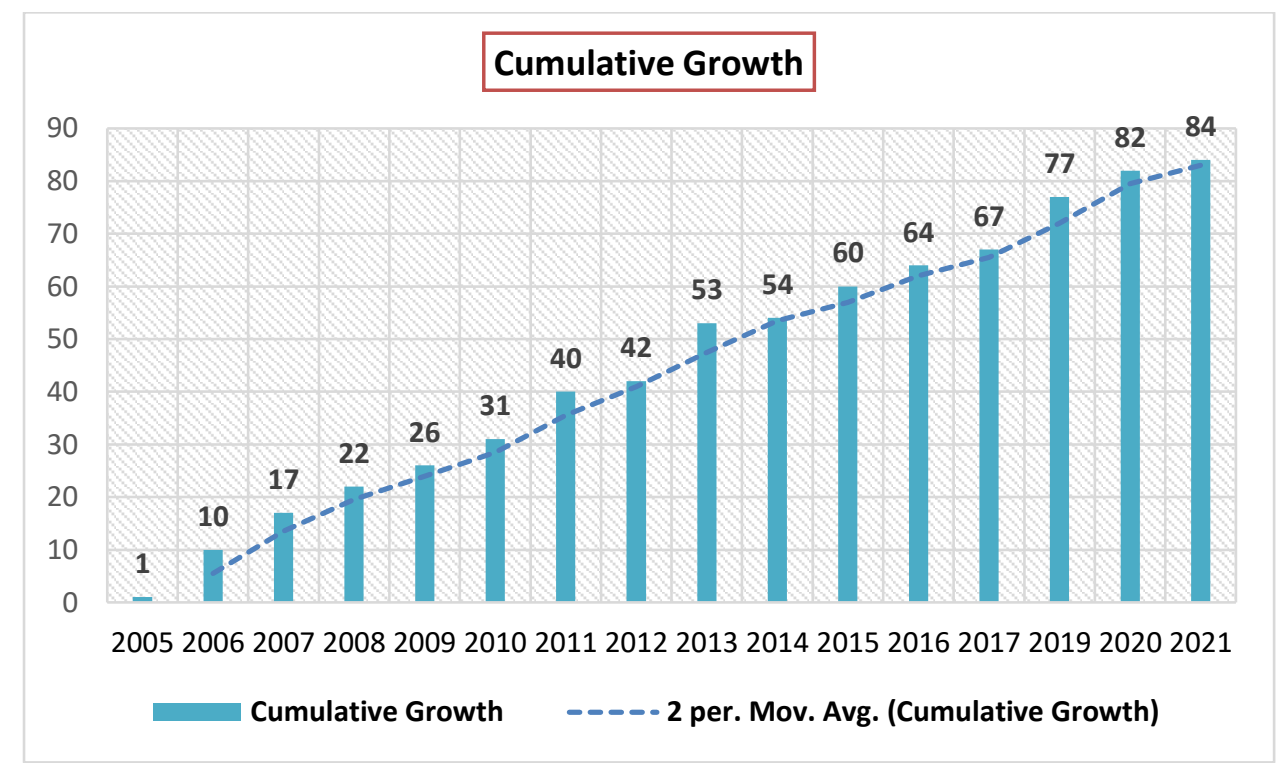

Figure 5: Cumulative Growth of Indian OAIRs

\section{Distribution of OAIRs State Wise}

Table 1 highlights the state-wise development of OAIRs in India. Maharashtra secured the first position with 16 (19.05\%) IRs, followed by Delhi State with 15 (17.86\%) IRs on rank 
two, Karnatka state on the third rank with 11 (13.10\%) IRs. Though Chandigarh, Haryana, Jammu and Kashmir, and Jharkhand are the least contributor states, each with only one OAIR.

Table 1: Distribution of OAIRs State Wise

\begin{tabular}{|c|l|r|r|}
\hline SN & State & No. of OAIRs & Percentage \\
\hline 1 & Maharashtra & 16 & 19.05 \\
\hline 2 & Delhi & 15 & 17.86 \\
\hline 3 & Karnataka & 11 & 13.1 \\
\hline 4 & Gujarat & 7 & 8.33 \\
\hline 5 & Kerala & 6 & 7.14 \\
\hline 6 & Telangana & 5 & 5.95 \\
\hline 7 & Uttar pradesh & 4 & 4.76 \\
\hline 8 & Odisha & 3 & 3.57 \\
\hline 9 & Tamil Nadu & 3 & 3.57 \\
\hline 10 & Uttarakhand & 3 & 3.57 \\
\hline 11 & West Bengal & 3 & 3.57 \\
\hline 12 & Goa & 2 & 2.38 \\
\hline 13 & Punjab & 2 & 2.38 \\
\hline 14 & Chandigarh & 1 & 1.19 \\
\hline 15 & Haryana & 1 & 1.19 \\
\hline 16 & Jammu and Kashmir & 1 & 1.19 \\
\hline 17 & Jharkhand & 1 & 1.19 \\
\hline & Total & $\mathbf{8 4}$ & $\mathbf{1 0 0}$ \\
\hline & & & \\
\hline
\end{tabular}

\section{Repositories according to their Software}

According to the result (see figure 6), OAIRs in India use four different types of software, viz. DSpace, Drupal, E-prints, and Greenstone. DSpace is the most popular software among these four, adopted by $58 \%$ (49) of the total. E-prints is the second most common (34\% or 29 ), followed by Drupal and Greenstone, each with $1 \% .3 \%$ of repositories have not indicated their software, and $2 \%$ are using other than the software mentioned above. 


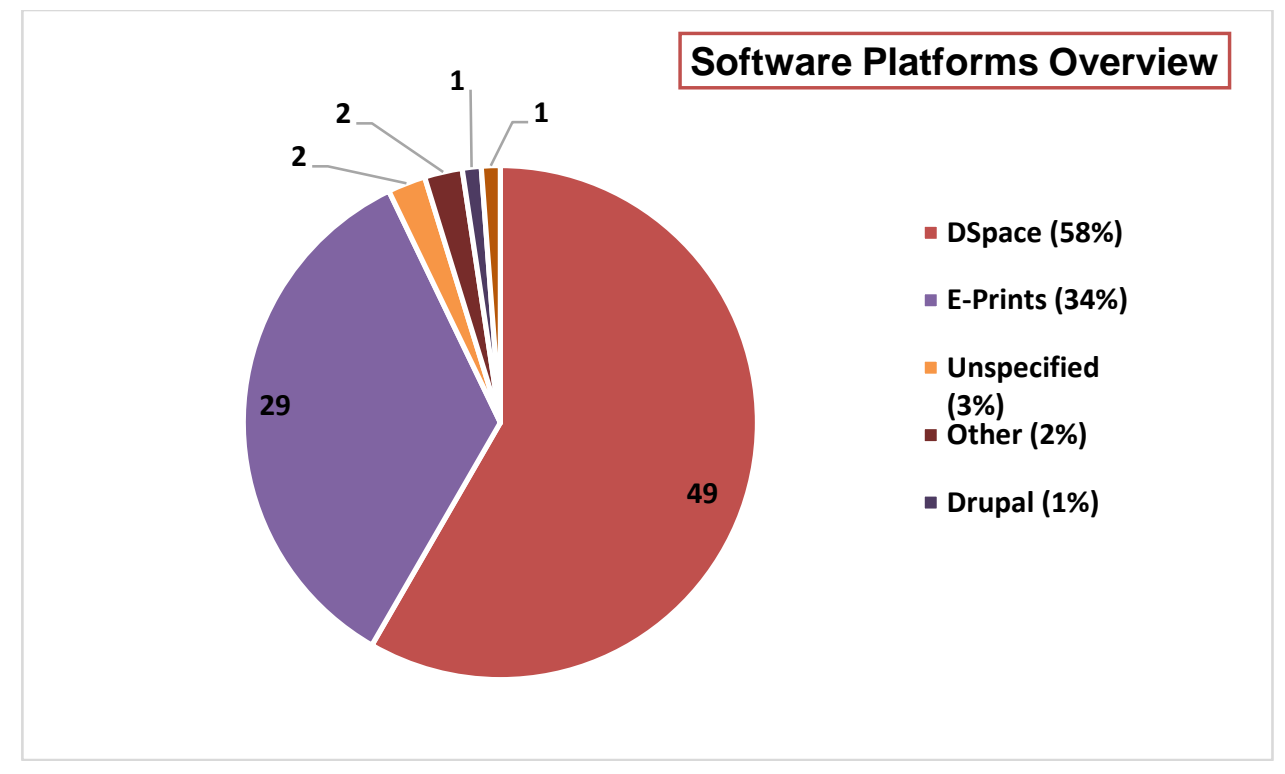

Figure 6: Software Platforms Overview

\section{Repositories according to their Contents}

After analyzing the statistics from openDOAR, it was observed (see figure 7) that the Indian OAIRs deposit a total of 12 different types of content. The majority of the repositories (i.e. 58 or $70.73 \%$ ) covered Journal Articles, followed by Theses \& dissertations, Conference \& workshop papers with coverage of $44(53.65 \%) \& 38$ $(46.43 \%)$, respectively. Datasets with $0.02 \%(2)$ is the least covered one.

\section{Overview of Content Type}

Journal Articles (58)

Theses and Dissertations (44)

Conference and Workshop.

Other Special Item Types (25)

Learning Objects (19)

Bibliographic References (12)

Patents (5)

Datasets (2)

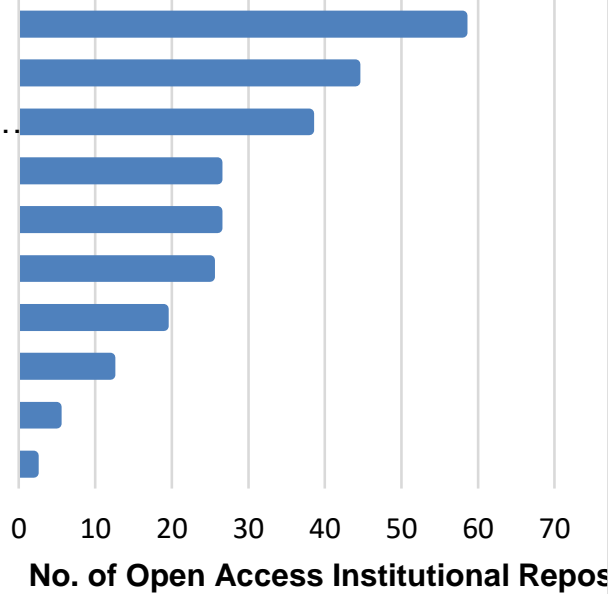

Figure 7: Overview of Content type

\section{Repositories according to their Subject Area}


If the subject area of the Indian OAIRs is considered, the majority revealed the coverage of multidisciplinary aspects or includes more than one type of subject area (if specified). Out of the total 24 types of different subject areas identified from OpenDOAR (see figure 8 ), the majority of the repositories (46 or $54.76 \%$ ) are Multidisciplinary. Again, subject areas like Law \& Politics and Education under Social Science General are the least covered (1 or $1.19 \%)$ among all.

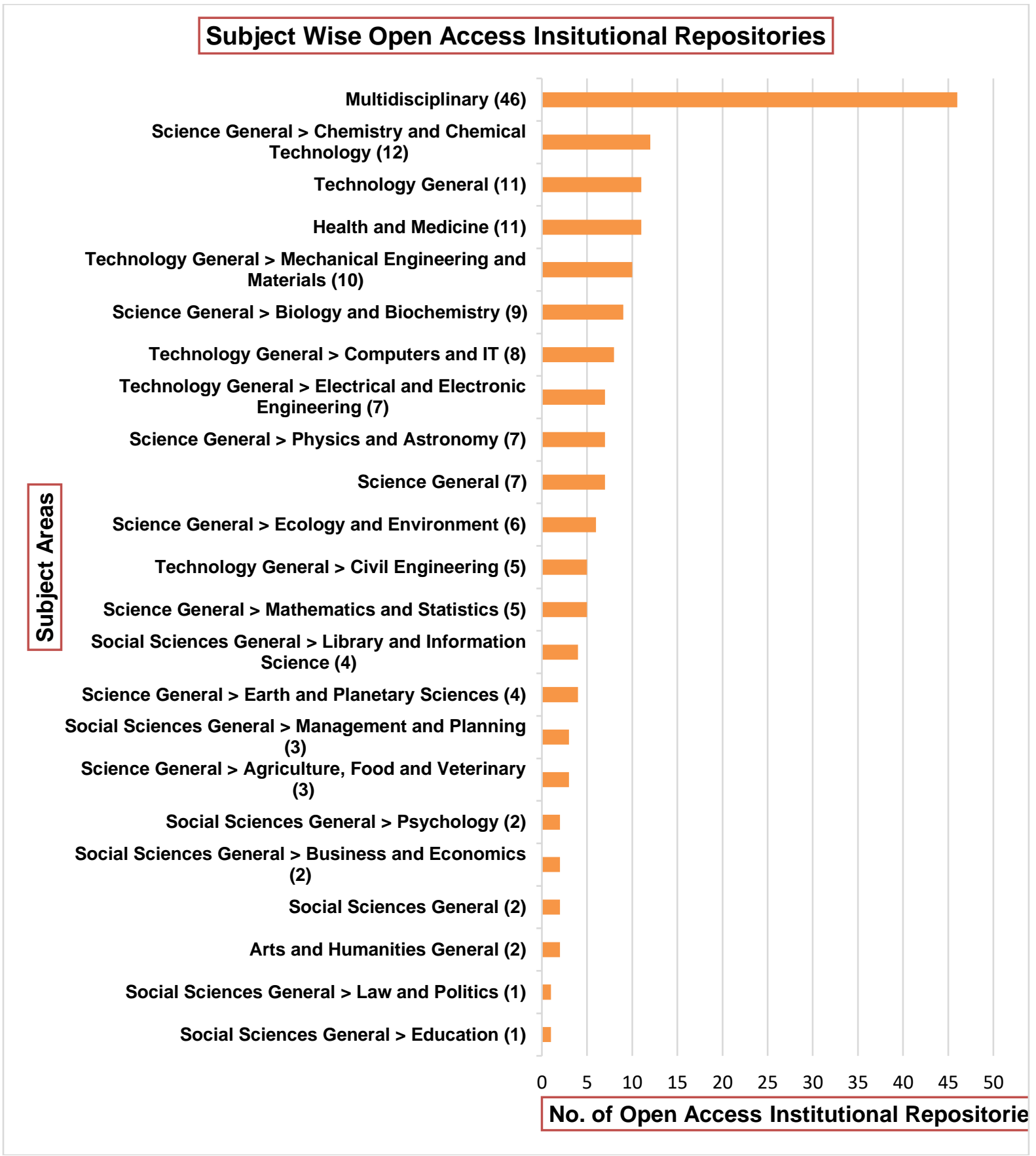

Figure 8: Subject Wise Open Access Institutional Repositories

\section{Repositories according to their Language}


The current study revealed that the Indian OAIRs cover content in more than one language in their repository. Out of 10 differently identified languages (see figure 9), the majority of the repositories (96.43\%) among 84 provide their content in English, followed by Hindi used by $6(7.14 \%)$ repositories. On the other hand, contents with Sanskrit, Kannada, Gujrati, Bengali \& Arabic languages covered by a single repository each.

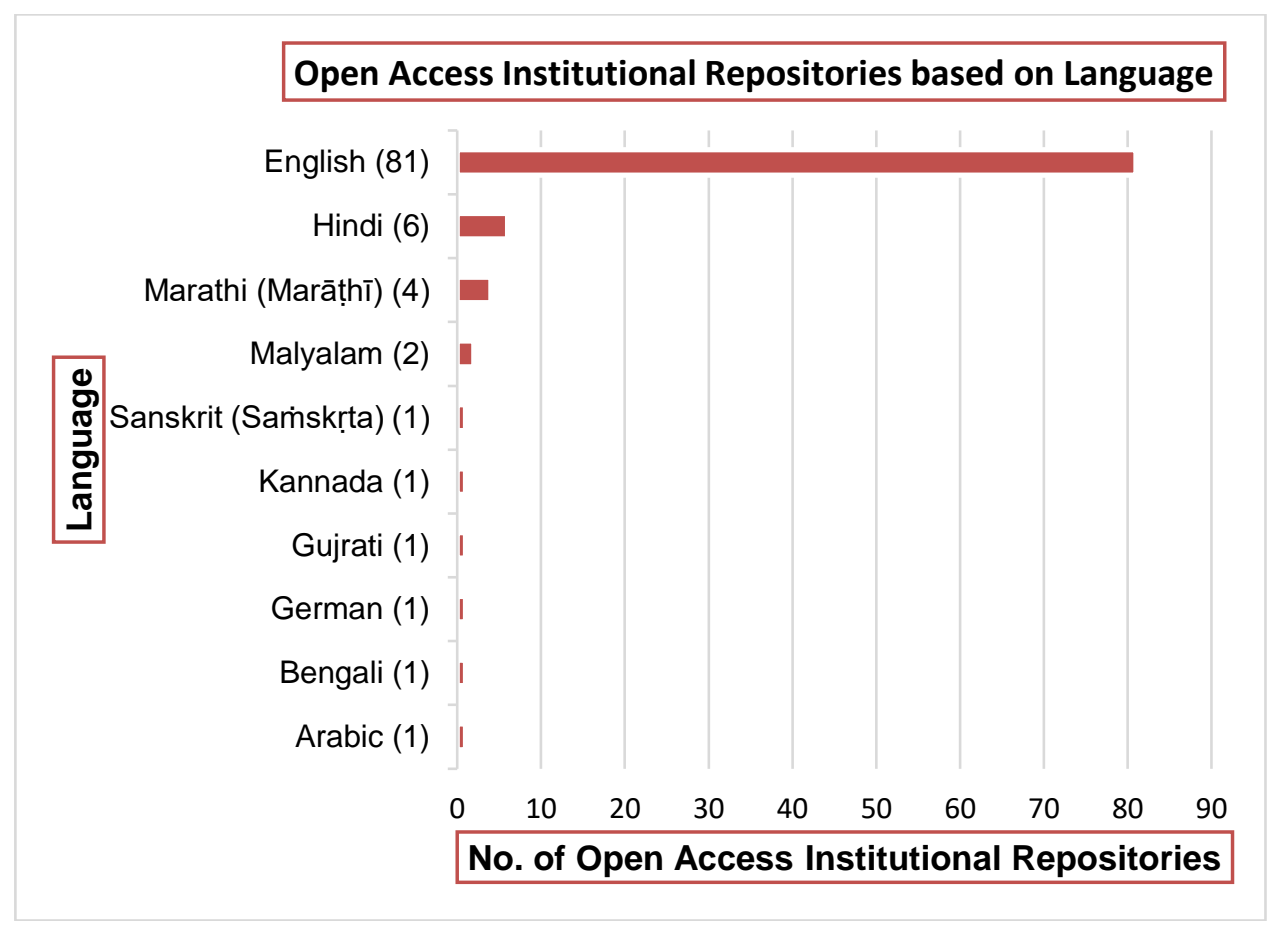

Figure 9: Open Access Institutional repositories based on Language

\section{Repositories according to their last date of modification}

To cope with the latest technology \& requirements and to prevent from being obsolescence, timely updation \& modification of the repositories is important. The study inferred that most of the OAIRs (61 or $72.62 \%$ ) undergo a recent modification on 18 February 2021. The second most recent modification was done on 23 November 2020 by only one repository and two repositories not specified their last date of modification. The rest of the 29 repositories have not been modified since 2019 as per the stats provided by OpenDOAR (see figure 10). 


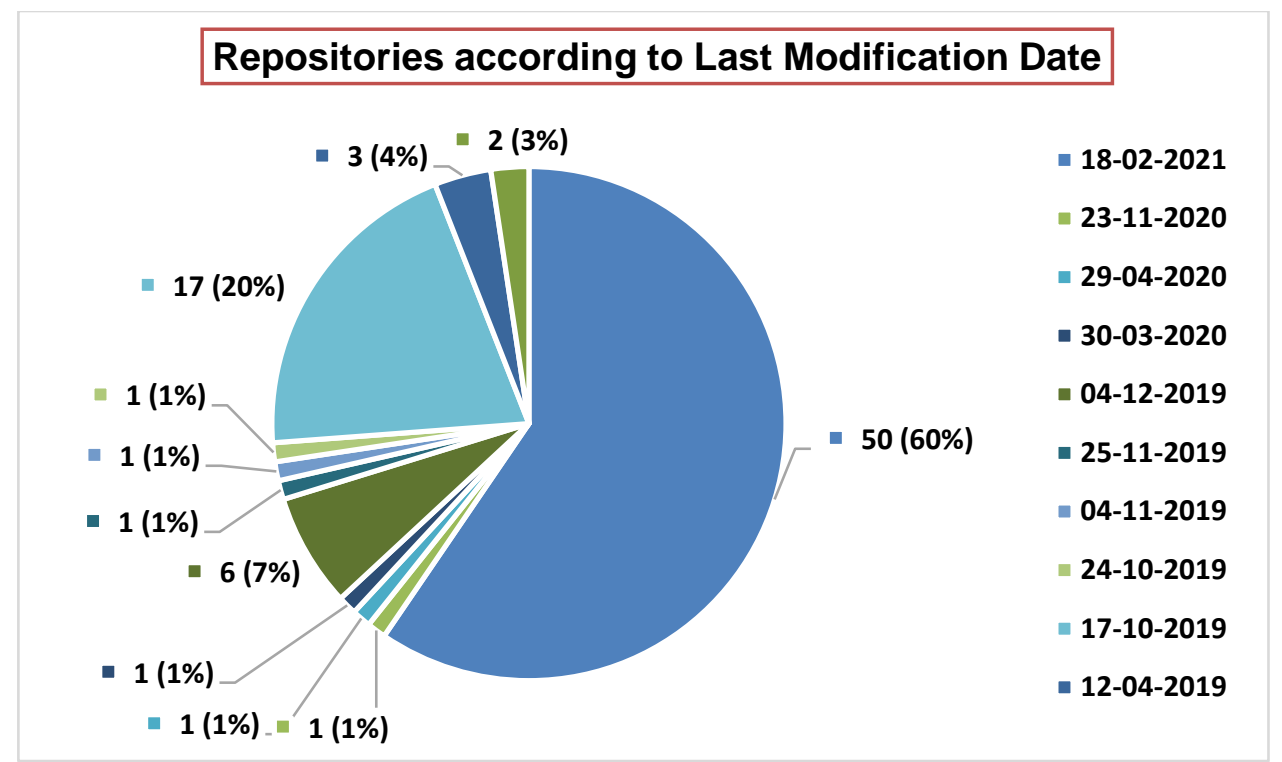

Figure 10: Repositories according to Last Modification Date

\section{RESULTS OF THE SURVEY}

After the survey done, the survey data was collected \& imported as a .csv file (Google sheet) for further analysis and visualization using spreadsheet software. It aims to organize, classify and summarize the data being collected for better comprehension and interpretation leading to understand and explore answers or solutions to the survey questions (SQs) which originally triggered the research.

\section{SQ 1: Are you aware about the Open Access Insitutional Repository (OAIR), OpenDOAR AND ROAR?}

The primary purpose of the user's study is to identify the effectiveness of OAIRs in the academic \& education system. To find out the actual user \& to set the target group concerning their richness $\&$ value, SQ1 provides a platform to judge the awareness of the sample users about OAIR, OpenDOAR \& ROAR. 


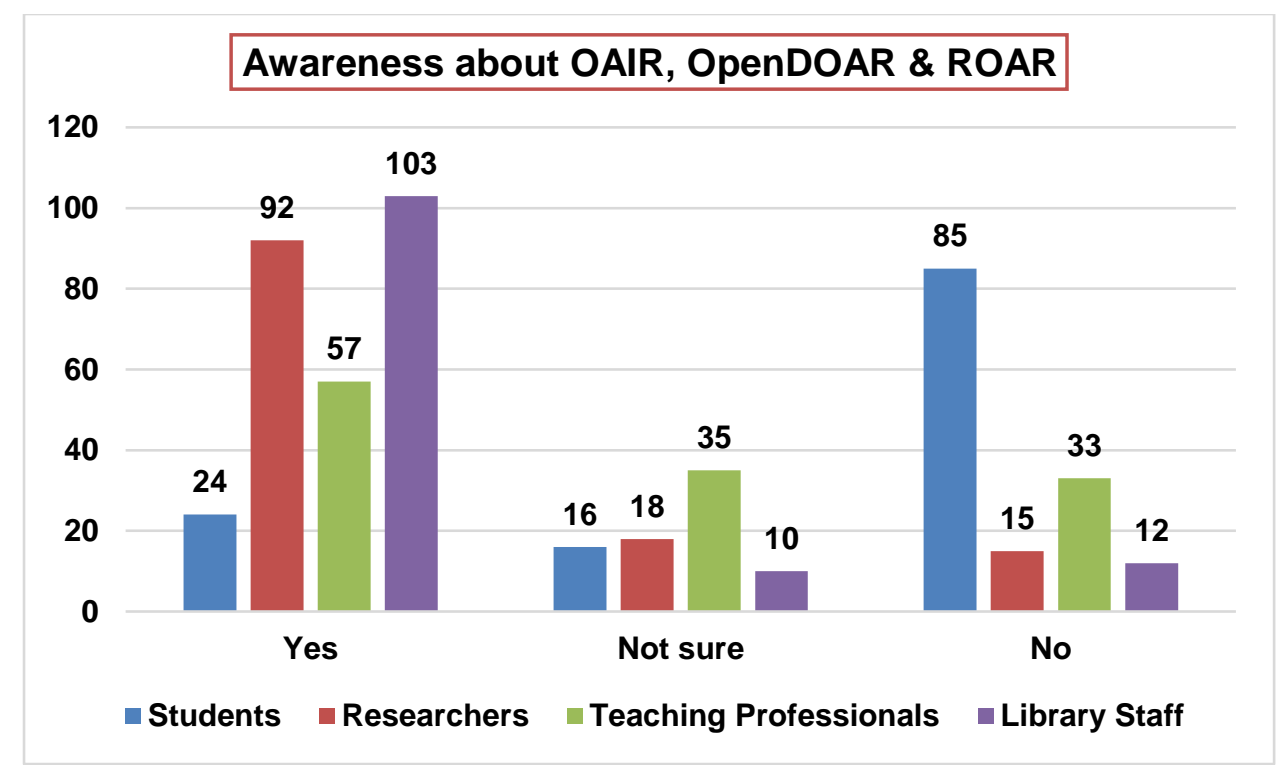

Figure 11: Awareness about OAIR, OpenDOAR \& ROAR

From figure 11, it is identified that the Students with a $19.2 \%$ (24) awareness rate are the least valuable users among the four. On the other hand, most of the Library Staff $103(82.4 \%)$ are aware of OAIR, OpenDOAR \& ROAR, followed by Researchers (92 or 73.6\%) \& Teaching Professionals (57 or $45.6 \%$ ). For future reference, it can be noted that the students of all streams should be awared about the OAIR \& its benefits in the digital era through webinars, workshops \& other outreach programmes.

\section{SQ 2: How frequently do you visit OAIR during COVID-19 Pandemic?}

In this pandemic period, the closure of educational institutions \& lack of physical resources caused an increasing demand for OAIRs as a free to use platform with a high volume of e-content. Thus OAIRs become an invaluable resource for all type of target users, viz Student, Researcher, Teaching Professional \& Library Staff. SQ 2 deals with the frequency of visiting OAIR during COVID-19. 


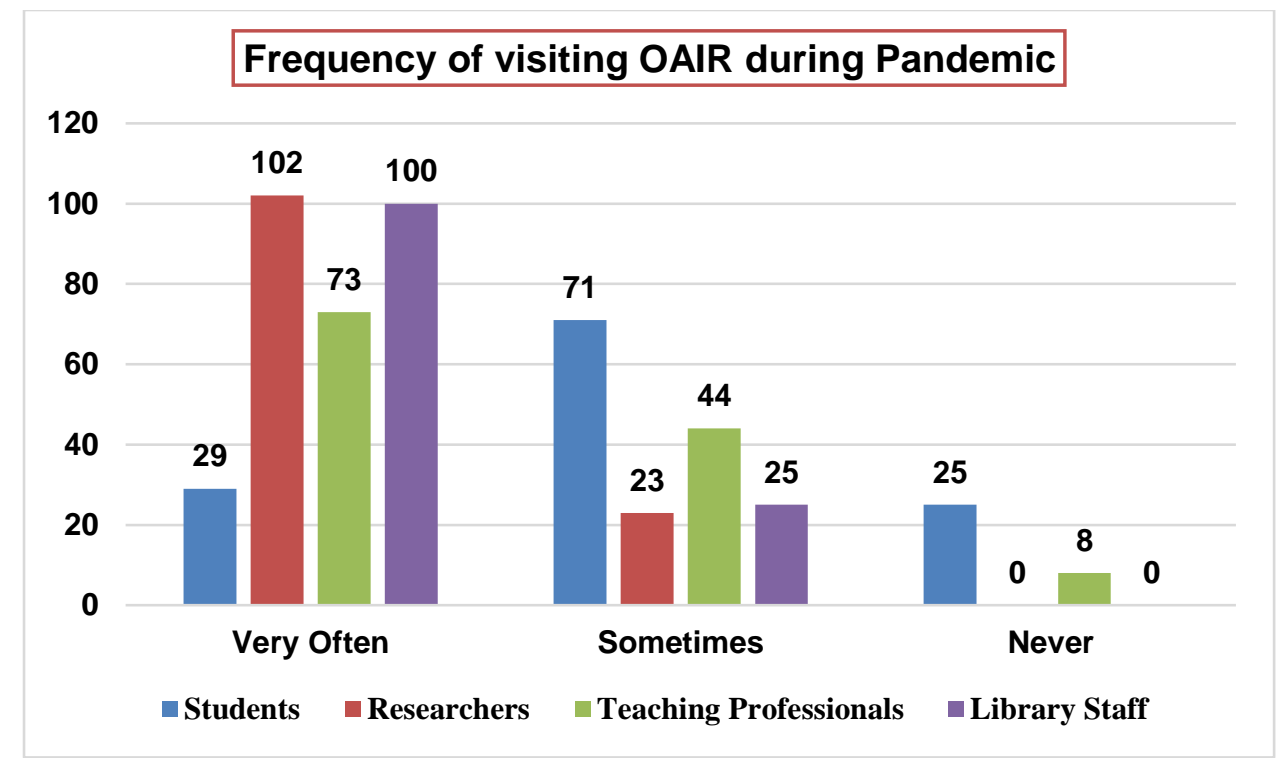

Figure 12: Frequency of visiting OAIR during Pandemic

Figure 12 identifies that under the frequency range "Very Often", 81.6\% (102) of Researchers and $80 \%(100)$ of Library Staff covered themselves. The percentage is $58.4 \%$ (73) for Teaching Professionals and decrease steeply to $23.2 \%$ (29) in the case of Students. Moreover, it is also noted that $35.2 \%$ (44) of Teaching Professionals visit OAIRs sometimes and $20 \%$ (25) of Students never visit OAIRs. This result suggests that only Researchers and Library Staffs visited OAIRs regularly, while Teaching Professionals are moderate visitors and Students are the least one.

SQ 3: Do you think OAIR is an invaluable information source for supporting Academic \& Educational system in this "new normal"?

SQ 3 tries to identify the effectiveness of OAIRs to encounter the shifting of the education system from traditional to online, in this current situation of a pandemic outbreak. The study reveals that all the Library staff members agree with this point of view. Also 124(99.2\%) Researchers, 103(82.4\%) Teaching Professionals \& 62(49.6\%) Students agrees with SQ3. Unfortunately, only 9 Students and 7 Teachers do not agree with SQ3. 


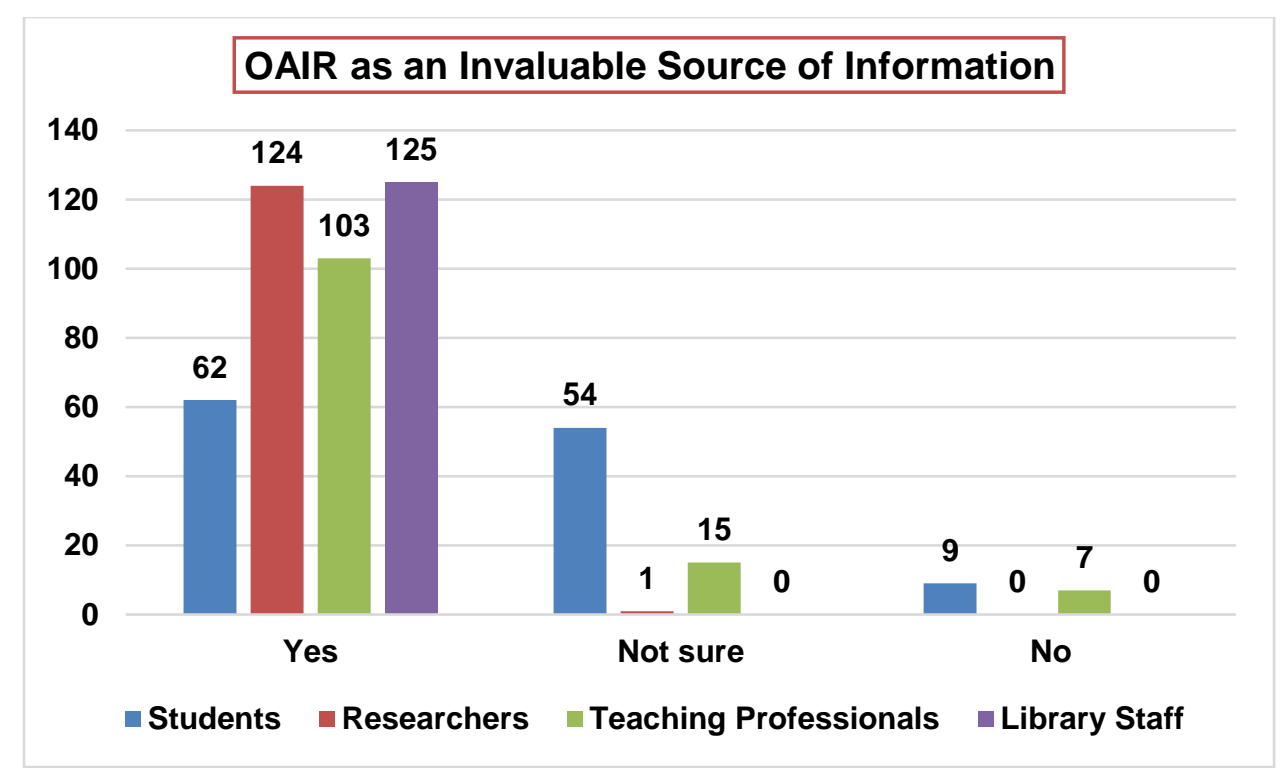

Figure 13: OAIR as an Invaluable Source of Information

SQ 4: In Pandemic situation, what are benefits of An OAIR from user point of view?

To identify the actual benefits of the OAIRs during pandemic, SQ4 structurise as a closedend question keeping in view different views of the different categories of the target samples. It can be noted from the result that almost all categories of users viz Students, Researchers, Teaching professionals \& Library staff agrees that OAIR is free of cost, increase the volume of available material, available anywhere at any time with easily retrievable content. Only some variation observed in the free of copyright and licensing restrictions option. 


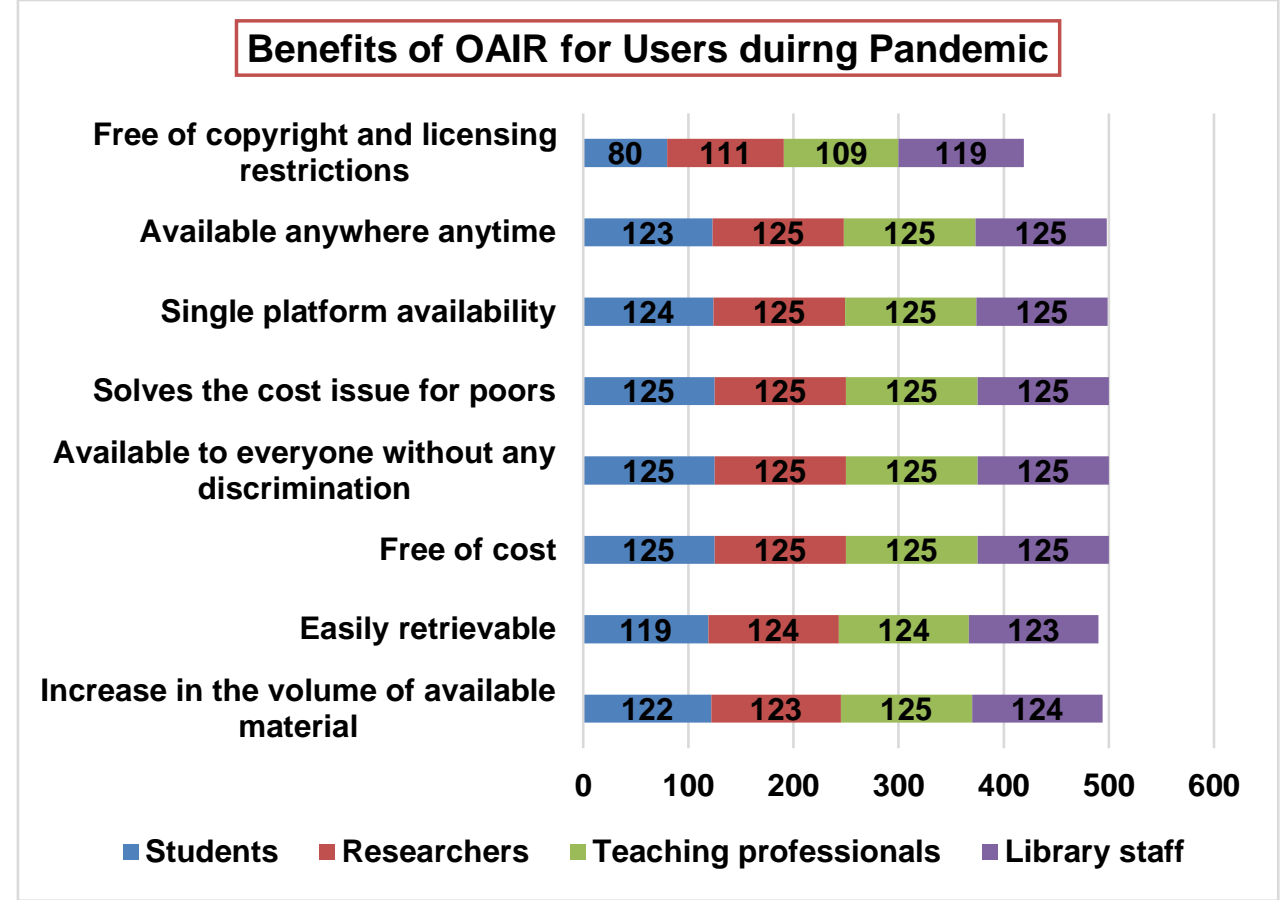

Figure 14: Benefits of OAIR for Users during Pandemic

SQ 5: What type of content do you search in an OAIR during Pandemic period?

SQ5 is another closed-end question that examined which type of contents searched most during this pandemic period. The selection of the options for SQ5 purely based on the commonly available content types of Indian OAIRs in OpenDOAR.

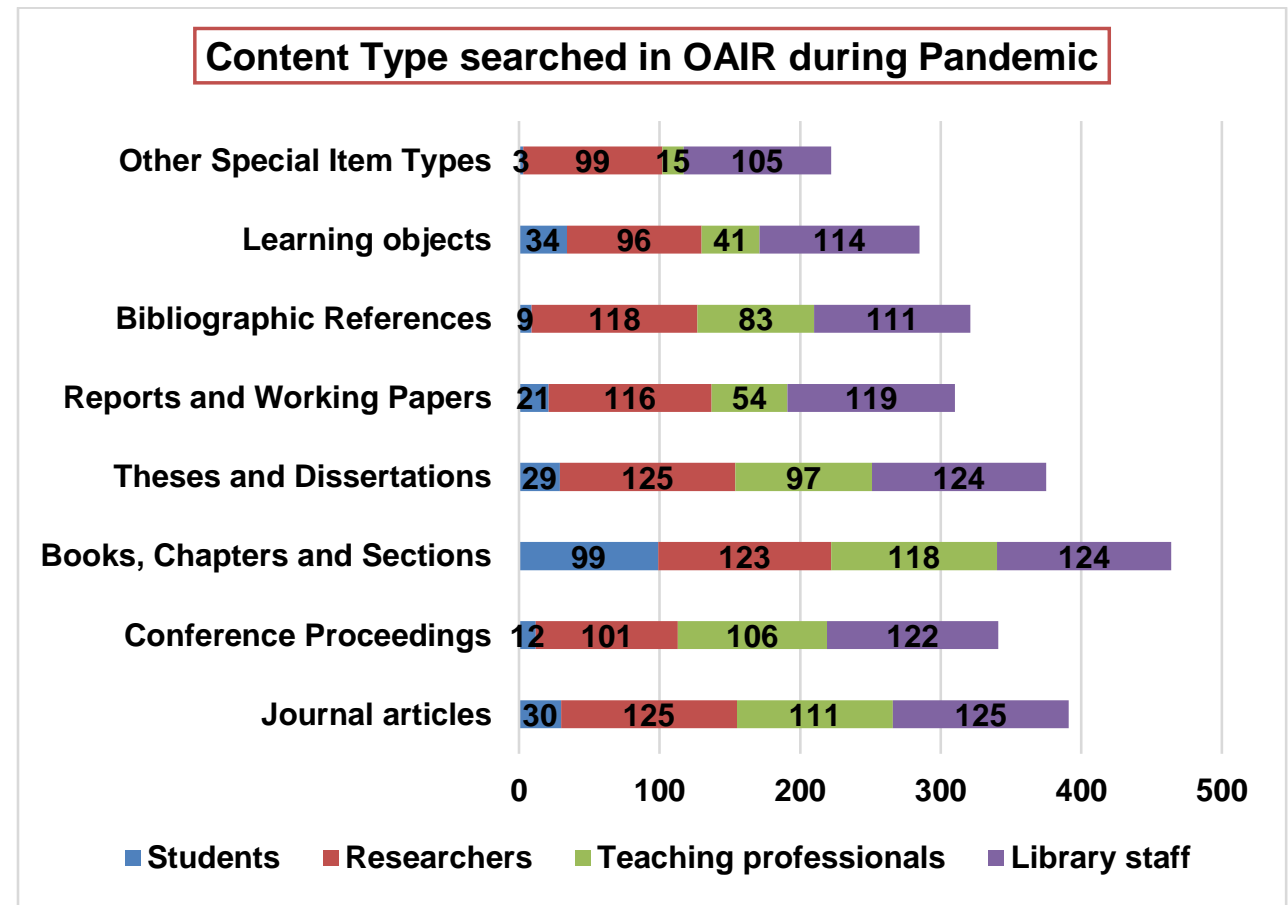

Figure 15: Searched Content type in OAIR during Pandemic 
Figure 15 shows that Researchers and Library Professionals are the most frequent visitors of each of the contents listed in SQ5. Overall, surprisingly Books, Chapters \& Sections are searched most (92.8\%) rather than Journal Article (78.2\%), Thesis and Dissertations (75\%) or Conference Proceedings (68.2\%). These four above-mentioned content types are most widely used by teaching professionals for their teaching-learning purposes, whereas students rely on Books, Chapters, and Sections for their assignments.

SQ 6: In this financially critical situation, do you think OAIR can act as a significance alternate for promoting Web accessibility \& eliminate Digital divide?

Due to this recent spike of COVID-19, the Indian economy encounters a steep fall in the fiscal year 2020-21 and badly affected the financial situation of both the employee \& the Institution. In this situation of individual-level financial crisis \& lack of financial support from the Institution, SQ6 tries to find the efficiency of OAIRs as an alternate to support the academics \& education system.

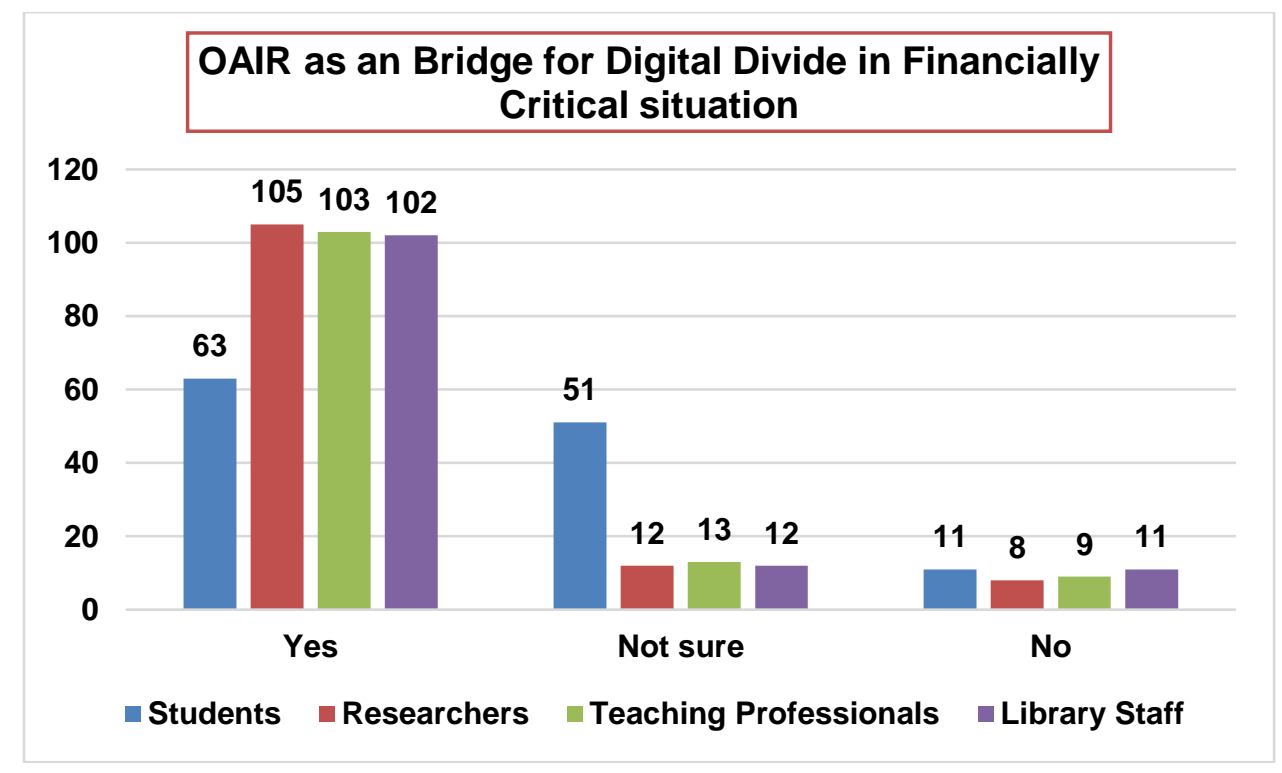

Figure 16: OAIR as an Bridge for Digital Divide in Financially Critical situation

It can be observed from figure 16 that $84 \%$ (105) Researchers, 82.4\% (103) Teaching Professionals, $81.6 \%$ (102) Library Staff and 50.4\% (63) Students agrees with the view that by making content freely accessible on the web, OAIRs act as a bridge to fill the gap of the digital divide in this online study system.

SQ 7: Are you aware of the copyright agreement signed with the publishers while publishing in Open access Institutional Repository?

Availability of a sufficient amount of scholarly content is an essential requirement to make any OAIR successful. So, it is necessary to have a look at the awareness of the copyright agreement signed with the publishers while publishing in an OAIR. 


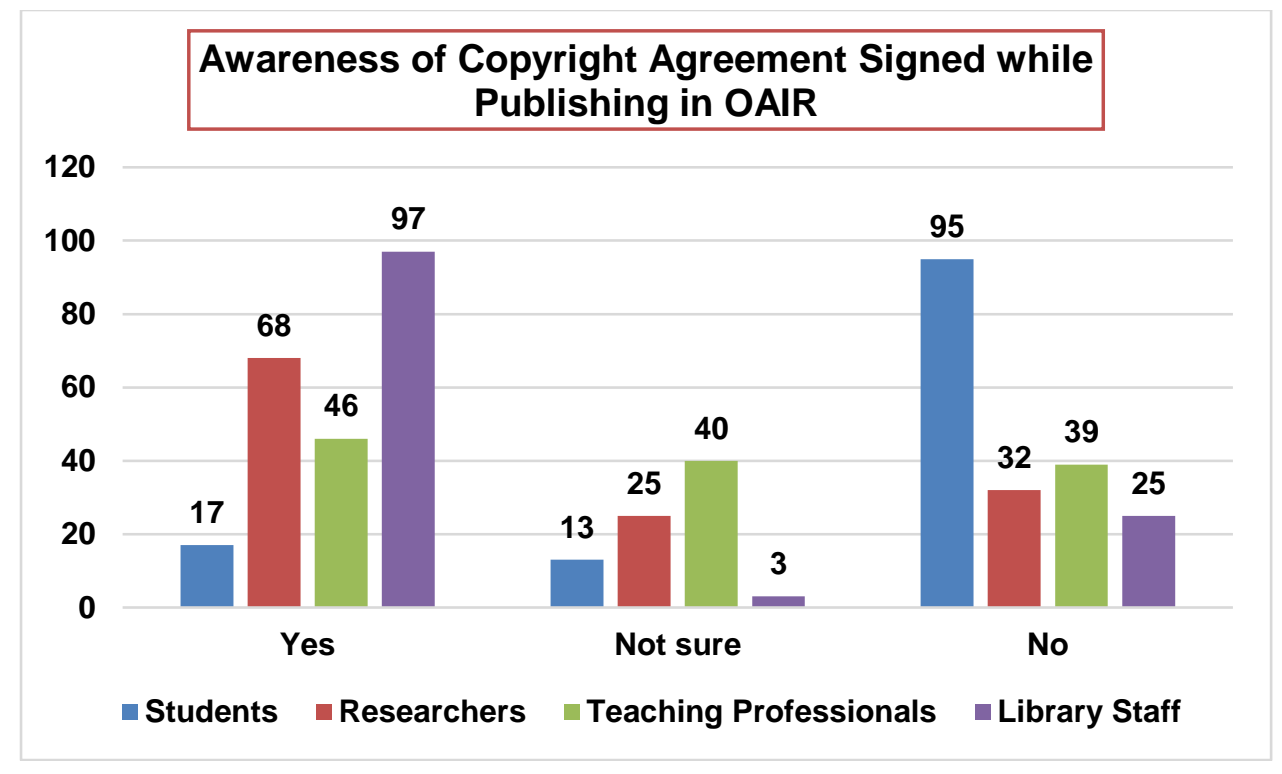

Figure 17: Awareness of Copyright Agreement Signed while Publishing in OAIR

Figure 17 reveals that Library Staff being the information providers are the most knowledgeable about the copyright agreement while publishing in OAIR lead by Researchers. Nearly $77.6 \%$ (97) of Library Staff admitted that they have sufficient knowledge about this copyright agreement. While the percentage is $54.4 \%$ (68) for the Researchers \& $46(36.8 \%)$ of Teachers are aware of the same. Unfortunately, most of the students $(76 \%)$ are unaware of this copyright agreement due to a lack of practical knowledge.

SQ 8: Do you know SHERPA RoMEO (http://www.sherpa.ac.uk/romeo) provides a useful quick reference guide for you to check on open access and self-archive restriction and policies with links to publishers' websites?

SQ 8 deals with the awareness of SHERPA RoMEO among different categories of targeted samples. And results from the survey are not up to the mark as expected. It can be seen from figure 18 that more than 70 respondents from each category except Library Professional lack knowledge of SHERPA RoMEO. And some of them are not sure. Just 63.2\% (79) of Library Professionals are aware of this website, which is a disappointing response even though this is the most aware category among all others. And students are the category with the least knowledge of the same. 


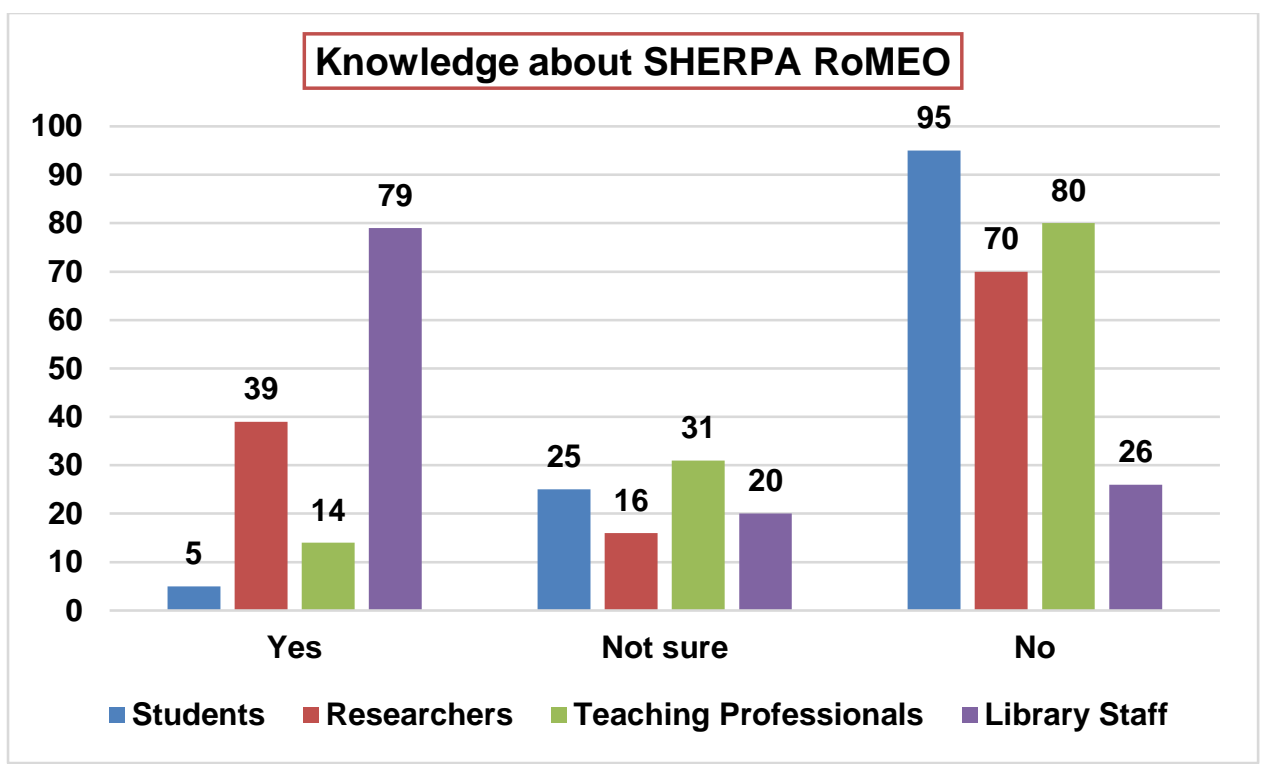

Figure 18: Knowledge about SHERPA RoMEO

\section{SQ 9: How OAIR helps library professionals in improving their services during Pandemic?}

Free and easy to access characteristics of OAIRs with a large volume of contents helps library professionals to cope up with the new trend of information request during this pandemic situation. Though primarily, it can be assumed that SQ9 is intended only for library professionals, the users' of the service also acquire some knowledge of the same. Students, researchers, teaching professionals, and other library staff benefit from the services provided by Library Professionals. In this lockdown period and financially critical situation OAIR has eased the work of Library professionals to a great extent. Each of the eight options of SQ9 gets at least more than 100 responses from each category. It acknowledges that OAIRs are a boon to library services in this financially precarious situation, supporting teaching, learning, and research by providing single-platform access to voluminous content. 


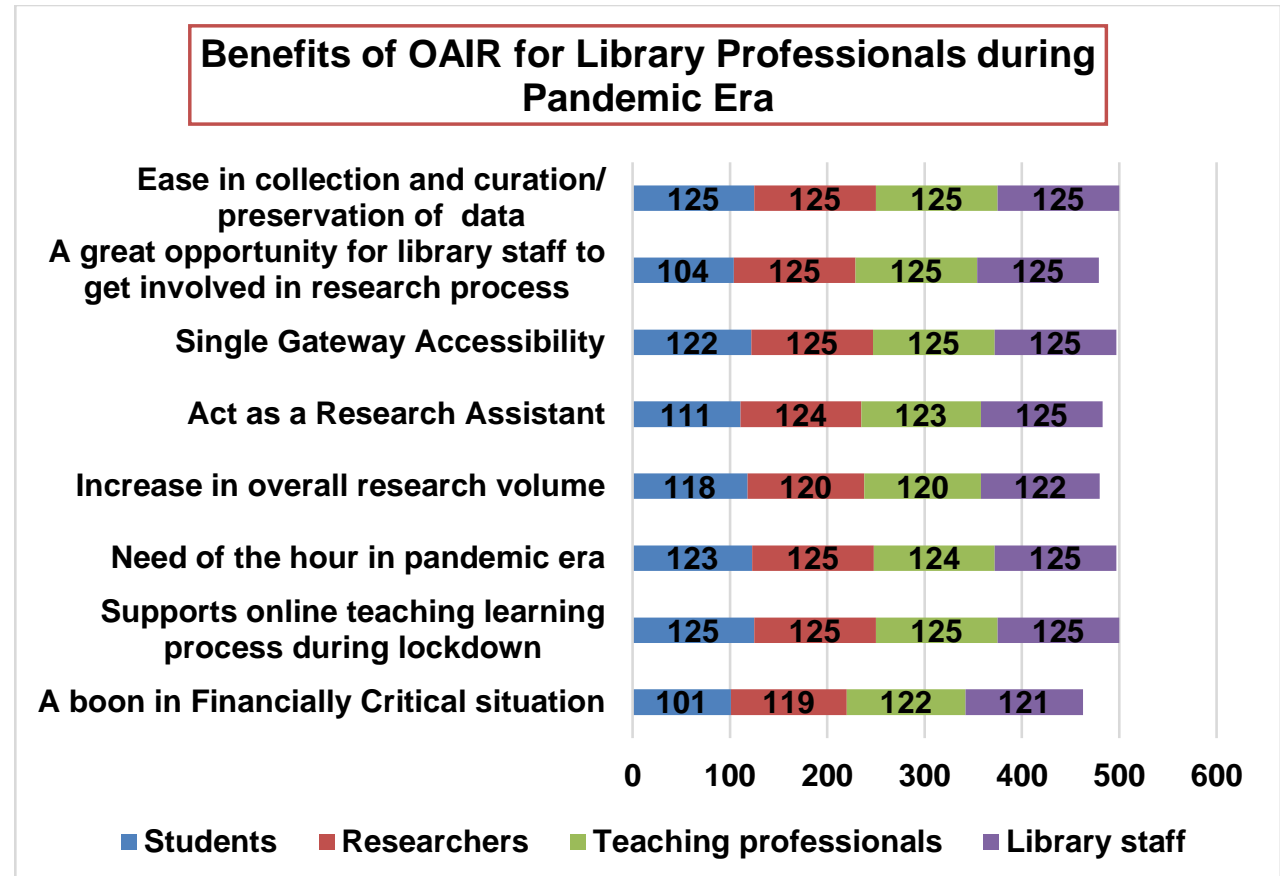

Figure 19: Benefits of OAIR for Library Professionals during Pandemic Era

\section{SQ 10: Compare the effectiveness of an OAIR in different situations (1 to 5)}

A comparative analysis was conducted using SQ10 to compare the effectiveness of Indian OAIRs during different Pre-Pandemic, Pandemic and Post-Pandemic Period. Only the regular and known users of OAIRs can do some value addition to the research question. Figure 20 illustrates that OAIR was most effective for researchers and library staff during the pre-pandemic era, but its effectiveness for students and teaching professionals increased at a faster pace during the pandemic period. Additionally, the effectiveness of OAIR during Pandemic and Post Pandemic Period is almost similar for all categories.

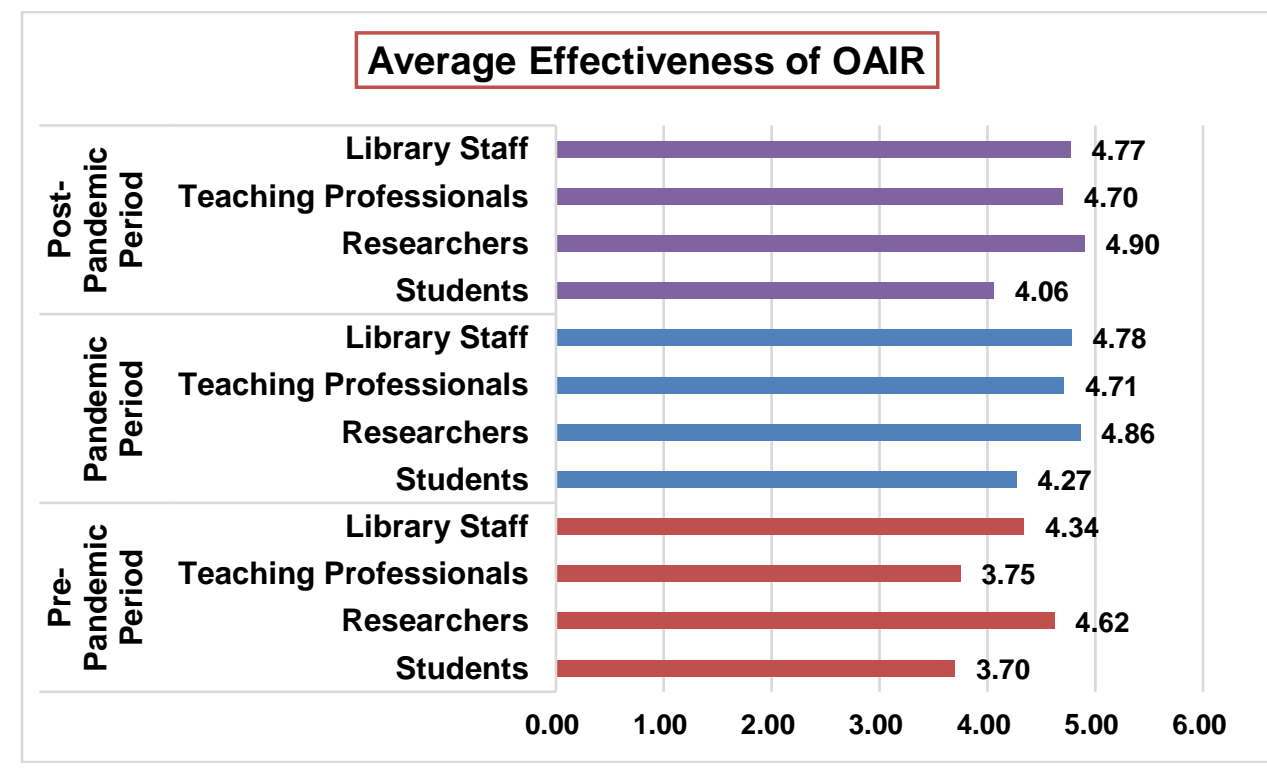


Yanti Idaya, AMK., et al. (Eds.): ICOLIS 2021, Kuala Lumpur: DLIS, FASS, 2021

Figure 20: Average Effectiveness of OAIRs in Different Time Period

\section{KEY FINDINGS OF THE STUDY}

- It can be revealed from the study that according to OpenDOAR database there are total of 84 OAIRs in India. Most of them are using DSpace and E-Print software.

- There is a consistent growth of Indian OAIRs in OpenDOAR and most of them are updated with time.

- Teaching professionals required to give more importance towards the usage of OAIRs and students need more awareness about the benefits of it.

- OAIR effective during COVID-19, need to aware publishers about copyright, publishing policies of Open Access Institutional Repositories, and SHERPA RoMEO.

- Indian OAIRs played a significant role in promoting web accessibility and eliminating digital divide in this changing system of education.

- During pandemic an invaluable source of information specially in era of digital India.

- Repositories should focus more on the other types of content along with the Journal articles and theses \& dissertation to attract more students and teaching facility and should provide content in other Indian languages too other than English

\section{CONCLUSION}

In the face of the COVID-19 pandemic, the utility and necessity of OAIRs have manifolded in India. Indian OAIRs have been effective during the pandemic in assisting online teaching by providing open access resources without discrimination at zero cost. In this way, OAIRs helped in eliminating the digital divide in this financially critical situation. The study revealed that the regular updation of Indian OAIRs make them suitable for every single change made in the Indian Education system. Furthermore, the availability of diverse content types in a variety of subject categories aids the Indian OAIRs in enriching a knowledge base for academics.

Now, while organisations such as UNESCO are developing an existing mandate on guaranteeing universal access to information in the fight against COVID-19 (UNESCO 2020), some academics may be hesitant to initiate open accessibility due to concern of disrupting excellent ties with their publishers (Adolphus 2009). In this situation, an institution should promote the building of OAIRs as an essential mandate to digitally archive the intellectual product created by the faculty, research staff, and students of the institution and freely accessible to end users both within and outside of the institution (Narayana, Biradar, and Goudar 2006). But still, there is a need to conduct various awareness programs about OAIRs to attract more users, especially the students and teachers. Moreover, institutions should amend regulations for their researchers \& academicians to publish institutional funded research in an open-access journal/database.

\section{REFERENCES}


Adewole-Odeshi, Egbe, and Okeoma Chinelo Ezechukwu. 2020. "An Analytical Study of Open Access Institutional Repositories in Nigerian Universities." Library Philosophy and Practice. https://digitalcommons.unl.edu/libphilprac/3884.

Adolphus, Margaret. 2008. "Institutional Repositories." Emerald Publishing. 2008. https://doi.org/10.1108/03055720310509064.

Bhat, Mohammad Hanief. 2010. "Open Access Repositories: A Review." Library Philosophy and Practice. https://digitalcommons.unl.edu/libphilprac/356.

C., Shajitha, and Abdul Majeed K.C. 2021. "Institutional Repositories in South India: An Exploratory Study." Global Knowledge, Memory and Communication. Published ahead of print, January 29, 2017. https://doi.org/10.1108/GKMC-07-2020-0099.

CCSDS Secretariat. 2012. "Reference Model for an Open Archival Information System (OAIS)." Recommendation for Space Data System Practices. 2012. https://public.ccsds.org/pubs/650x0m2.pdf.

Crow, Raym. 2002. "The Case for Institutional Repositories: A SPARC Position Paper." Scholarly Publishing 223: 1-37. https://www.researchgate.net/publication/215993546\%0D.

Gul, Sumeer, Shazia Bashir, and Shabir Ahmad Ganaie. 2020. "Evaluation of Institutional Repositories of South Asia." Online Information Review 44 (1): 192-212. https://doi.org/10.1108/OIR-03-2019-0087.

Gurikar, Rushmanasab, and Gururaj S. Hadagali. 2021. "Use of Open Source Software in Indian Institutional Digital Repositories: A Study." Library Philosophy and Practice (e-Journal). https://digitalcommons.unl.edu/libphilprac/4738 .

Jisc. n.d. "About OpenDOAR." OpenDOAR. Accessed April 26, 2021. http://www.opendoar.org/about.html.

Kalbande, Dattatraya Trayambak. 2019. "Institutional Repository in Open DOAR: Status Quo India." Library Philosophy and Practice (e-Journal). https://digitalcommons.unl.edu/libphilprac/2562.

Kalbande, Dattatraya Trayambakrao. 2012. "Institutional Repositories in India: An Overview." Online International Interdisciplinary Research Journal 2 (4): 194-203. https://oiirj.org/oiirj/july-aug2012/25.pdf.

Kathleen, Shearer. 2002. "A Guide to Setting-up an Institutional Repository." http://www.carl-abrc.ca/doc/Setting_up_an_IR.pdf.

Lee, Jongwook, Gary Burnett, Micah Vandegrift, Jung Hoon Baeg, and Richard Morris. 2015. "Availability and Accessibility in an Open Access Institutional Repository: A Case Study." Information Research 20 (1). http://www.informationr.net/ir/201/paper661.html\#.YQbUjo4zZPZ.

Murphy, Michael P.A. 2020. "COVID-19 and Emergency ELearning: Consequences of the Securitization of Higher Education for Post-Pandemic Pedagogy." Contemporary Security Policy 41 (3). https://doi.org/10.1080/13523260.2020.1761749.

Narayana, Poornima, B. S. Biradar, and I. R.N. Goudar. 2006. "Institutional Repositories in India: A Case Study of National Aerospace Laboratories." In Digital Libraries: Achievements, Challenges and Opportunities, edited by Shigeo Sugimoto, Jane Hunter, Andreas Rauber, and Atsuyuki Morishima, 533-34. Berlin, Heidelberg: Springer Berlin Heidelberg. https://doi.org/10.1007/11931584_67.

Nayak, Satyajit, Ayush Kumar Patel, Avadhesh Kumar Patel, and Bijayananda Pradhan. 2021. "Promoting the Educational Research through an Open Access Institutional Repository of Shanghai Cooperation Organisation (SCO) Countries: An Analytical Study." Library Philosophy and Practice (e-Journal). https://digitalcommons.unl.edu/libphilprac/5064. 
Panda, Subhajit. 2020. "Open Access Movement: A Probable Solution of Present Crisis in Scholarly Communications." International Journal of Library and Information Studies 10 (2): 174-185. https://doi.org/10.5281/zenodo.3950761.

Pinfield, Stephen. 2005. "A Mandate to Self Archive? The Role of Open Access Institutional Repositories." Serials 18 (1): 30-34. https://doi.org/10.1629/1830.

UNESCO. n.d. "Open Science Is Critical to the Fight against COVID-19." Accessed April 7, 2020.

https://en.unesco.org/covid19/communicationinformationresponse/opensolutio ns. 